\title{
Reduced effect of intravenous antibiotic treatment on sinonasal markers in pulmonary inflammation*
}

\author{
Franziska Doht ${ }^{1}$, Julia Hentschel'1,\#, Nele Fischer ${ }^{1}$, Thomas Lehmann², Udo R. \\ Markert ${ }^{3}$, Klas Böer ${ }^{4}$, Wolfgang Pfister ${ }^{5}$, Mathias W. Pletz ${ }^{6}$, Orlando Guntinas- \\ Lichius $^{7}$, Jochen G. Mainz ${ }^{1, \#}$ \\ 2 Institute of Medical Statistics, Computer Sciences and Documentation, Jena University Hospital, Germany \\ ${ }^{3}$ Department of Obstetrics, Placenta Laboratory, Jena University Hospital, Germany \\ ${ }^{4}$ Institute for Clinical Chemistry and Laboratory Diagnostics, Jena University Hospital, Germany \\ 5 Institute of Medical Microbiology, University of Jena, Germany \\ ${ }^{6}$ Center for Infectious Diseases and Infection Control, Jena University Hospital, Germany \\ Department of Otorhinolaryngology, Jena University Hospital, Germany
}

Rhinology 53: 249-259, 2015

DOl:10.4193/Rhino14.300

*Received for publication:

December 10, 2014

Accepted: January 29, 2015

\begin{abstract}
Background: Chronic bacterial rhinosinusitis is a common feature in Cystic fibrosis (CF) as mucociliary clearance in the sinonasal compartment is impaired. Aim of the present prospective study was to compare dynamics of inflammatory markers in the upper and lower airways (UAW/LAW) during systemic antibiotic therapy.
\end{abstract}

Methods: Nasal lavage and sputum of 16 CF-patients receiving an IV-antibiotic treatment against Pseudomonas aeruginosa and/ or Staphylococcus aureus were collected before and during treatment (median after 7.5 days). Cytological changes, DNA concentration, and inflammatory markers interleukin (IL)-4, IL-8, IL-13 and Myeloperoxidase (MPO) were assessed in samples from both airway compartments.

Results: Total cell count declined significantly in LAW-samples but not in UAW. Although MPO and IL-8 decreased significantly in both airway compartments, this was considerably more pronounced for LAW (median decrease MPO: LAW = 9.8-fold vs UAW = 1.75-fold, respectively; IL-8: LAW = 3-fold vs UAW = 1.9-fold, respectively).

Discussion: This is the first publication demonstrating substantially lower effects of IV-antibiotic treatment on sinonasal than on pulmonary inflammatory markers. Consequently, our findings highlight limitations of systemic antibiotic treatment to control infection in the sinonasal compartment. Primarily, we attribute this to the paranasal sinus' structure: these hollow organs, which in bacterial sinusitis are frequently filled with pus, mucoeceles and polyps, are not reached effectively by systemic antibiotic treatment.

Key words: Cystic fibrosis, upper airways, lower airways, nasal lavage, sputum, inflammation, cytokines, cytology

\section{Introduction}

Chronic rhinosinusitis (CRS), which is frequently associated with bacterial colonization of the upper airways (UAW) and paranasal sinuses is widespread, affecting $11 \%$ of the European and $13-17 \%$ of the US population ${ }^{(1-3)}$. Direct health care costs are estimated to be about 8.8 billion USD per year, not including indirect costs generated by antibiotic resistances, antibiotic-related complications or missed workdays ${ }^{(2,4)}$. CRS mostly affects immune competent patients and is associated to multiple factors such as air pollution, smoking or allergy ${ }^{(1,5)}$ but it is frequently associated to sinonasal pathogen colonization ${ }^{(3)}$. According to the assessment of different therapeutic strategies, incorporating the division in CRS with nasal polyposis (CRSwNP) and without nasal polyposis (CRSsNP), there is a lack of evidence for systemic antibiotics ${ }^{(3)}$. The only exception is the long-term use of macrolides in a low dose for CRSsNP based on macrolides 
immune-modulatory impact rather than on their antibacterial effect ${ }^{(3)}$

Cystic fibrosis (CF) is interesting as a model for CRS associated to bacterial infection as CF patients' upper (UAW) and lower airways (LAW) are colonized almost regularly with pathogens. Rhinosinusitis is a hallmark of this inherited disease ${ }^{(6-10)}$. The resulting prevalence of abnormal anatomy as seen in computer tomography reaches almost $100 \%$ while up to $50 \%$ of adult CF patients reveal nasal polyposis ${ }^{(10-13)}$.

$\mathrm{CF}$ as the most frequent life threatening autosomal recessive disorder among Caucasians ${ }^{(14)}$ is caused by a genetic defect of the cystic fibrosis transport regulator (CFTR) protein, a chloride channel across cell membranes. Altered ion composition leads to increased viscosity of secretions from exocrine glands of multiple organ systems. Regarding the respiratory system, which is most commonly affected, a consequential reduced airway surface liquid volume impairs mucociliary clearance ${ }^{(15)}$. Mucus retention allows pathogens like Staphylococcus (S.) aureus and Pseudomonas (P.) aeruginosa to remain in the airways and cause chronic excessive airway inflammation that leads to a progressive damage of lung parenchyma as major cause of morbidity and premature mortality in about $90 \%$ of patients $(9,16,17)$. Additionally, disorders like exocrine pancreatic insufficiency, diabetes, and hepatic involvement are frequent.

Recent studies demonstrated evidence of cross colonization among both airway compartments. In patients colonized in both airway levels with $P$. aeruginosa, Mainz et al. revealed identical genotypes in the UAW and LAW by $96 \%{ }^{(9)}$. This was confirmed by Johansen et al. ${ }^{\left({ }^{8}\right)}$ and others. Further recent studies have shown that CF patients who undergo lung transplantation regularly become re-colonized in their lung grafts from sinonasal reservoirs. $P$. aeruginosa clones in lung transplants were genotypically identical with those cultured before transplantation in both, the UAW and LAW ${ }^{(18,19)}$. These findings underline the thesis that CF upper airways are a gateway and a bacterial reservoir from where $P$. aeruginosa can spread into the LAW. Furthermore, paranasal sinuses may be a niche for adaptation, diversification and the development of antibiotic resistances of $P$. aeruginosa ${ }^{(20)}$. Hence, sinonasal involvement may play a key role in enhancing and maintaining chronic airway inflammation and the resulting aggravation of the clinical course. However, there appear to be differences in the pathophysiology of both airways levels. While the inflammation in lower airways is characterized by a neutrophil domination and high levels of IgG against $P$. aeruginosa, Johansen et al. showed that biofilms in the sinuses are surrounded by only a very few neutrophils, most likely as the result of an extensive IgA response in the upper airways ${ }^{\left({ }^{8}\right)}$. The authors propose that non-inflammatory properties of IgA may inhibit neutrophil recruitment in CF patients' sinuses leading to a reduced and more differentiated mucosal immune response. In contrast, the systemic inflammatory response in the LAW is characterized by neutrophil-dominated inflammation and the release of proteases and oxygen radicals $(8,21,22)$.

The use of intravenous antibiotics to treat and/or prevent pulmonary exacerbations in CF patients is well established and one of the major reasons for the increased life expectancy during the last four decades ${ }^{(23)}$. Elective IV-antibiotic therapy for eradication or reduction of the pathogen burden as well as the reduction of resulting inflammation is part of the standard care in many European CF Centers ${ }^{(24,25)}$.

The assessment of inflammatory markers in non-invasively collected nasal lavage (NL) and induced sputum (IS) of CF patients opens a field to monitor airway colonisation, host defence, inflammation, and the effects of therapeutic approaches. While IS has been considered repeatedly in the recent literature to be a useful method ${ }^{(26-28)}$, assessment of NL has been investigated rarely so far. NL is a well-tolerated, fast and cheap method to obtain airway surface liquid from the upper airways for microbiological and immunological issues ${ }^{(29)}$. According to the 'unified-airway-concept' a recent study by Fischer et al. showed that UAW assessment can have a predictive value for chronic pulmonary colonisation with P. aeruginosa ${ }^{(30)}$. Further on, Pitrez et al. discussed nasal wash as an alternative to bronchoalveolar lavage in detecting early pulmonary inflammation in children with $\mathrm{CF}^{(31)}$. Paats et al. stated that the determination of interleukin (IL)-6 and IL-10 in NL may provide an assessment tool for pulmonary exacerbations whereas Hentschel et al. were able to show a significant reduction of IL- 6 in the UAW during IV-antibiotic therapy, even after a median therapeutic time of 6 days ${ }^{(32)}$.

The aim of the present study was to investigate the changes in upper and lower airway inflammation during systemic IV-antibiotic treatment. As non-invasive methods, practicable within routine care, NL was applied for UAW sampling and IS for assessment of LAW infection and inflammation. Before and during early intravenous antibiotic therapy concentration of DNA, cytology and the expressions of the inflammatory mediators myeloperoxidase (MPO), IL-8, IL-4, IL-13, IL-17A, regulated upon activation normal T-cell expressed, and presumably secreted protein (RANTES or CCL5) as well as human soluble intercellular adhesion molecule-1 (sICAM or SCD54) were assessed and compared for both airway compartments.

\section{Patients, materials and methods}

Patients

Sixteen adult CF patients were recruited prospectively between August and December 2011, either during their stay at the University Hospital of Jena or during regular visits in the CF 
outpatient clinic. Inclusion criteria were an established diagnosis of CF based on two sweat tests and/or the recorded presence of two disease causing CFTR mutations as well as an intravenous antibiotic therapy planned to improve the clinical course of the patient. Written informed consent was obtained by patients before enrolment. The study was approved by the local ethics committee.

\section{Nasal lavage (NL)}

$\mathrm{NL}$ was performed as previously described ${ }^{(9)}$ using $10 \mathrm{~mL}$ of sterile saline ( $0.9 \% \mathrm{NaCl}$, Braun, Melsungen, Germany) per nostril. Processing was performed as described by Fischer et al. ${ }^{(30)}$. An aliquot was directly sent to microbiological analysis. After centrifugation the pellet was used for cytological analyses and the supernatant was stored in aliquots at $-80^{\circ} \mathrm{C}$ with protease inhibitors (Protease Inhibitor Mix G, SERVA Electrophoresis GmbH, Heidelberg, Germany) for immunological approaches.

(Induced) Sputum (IS)

Sputum was collected by spontaneous coughing or after induction by inhalation of $6 \%$ hypertonic saline (PARI GmbH, Starnberg, Germany). One aliquot was sent to microbiological analysis. Sputum was 1:5 weight-related diluted with sterile PBS, and homogenized by aspirating 20 times with an 18 Gauge cannula followed by additional 1:4 dilution using $0.1 \%$ Sputolysin (Merck, Darmstadt, Germany) and vortexing. The sputum was filtered with a $40 \mu \mathrm{m}$ cell strainer to remove debris and mucus. $1 \mathrm{ml}$ of filtrated sputum mixed with $100 \mu \mathrm{l}$ FCS was sent to cytological analysis. The remaining volume was centrifuged (400rpm, 7min, room temperature) and aliquots of the supernatant were stored at $-80^{\circ} \mathrm{C}$ with protease inhibitors.

\section{Microbiological, cytological, DNA and mediator analysis} Before IV-treatment nasal lavage and sputum were examined microbiologically according to European standards ${ }^{(32)}$. Physiological flora of the nasopharynx was considered as described recently ${ }^{\left({ }^{30}\right)}$. The definition of permanent and intermittent colonization $(50 \%$ or more of cultures and less than $50 \%$ of cultures within the preceding 12 months positive for a pathogen) was applied according to the criteria published by Lee et al. ${ }^{(33)}$.

Table 1. Clinical and serological characteristics of included patients (metric and ordinal variables).

\begin{tabular}{|c|c|c|c|c|c|}
\hline Metric and ordinal variables & $\mathbf{n}$ & mean & SD & median & Range \\
\hline Age (yr) & 16 & 26.25 & 4.597 & 25.0 & $21-37$ \\
\hline Weight (kg) & 16 & 56.84 & 9.5 & 55.95 & $45.3-72.0$ \\
\hline Height $(\mathrm{cm})$ & 16 & 160.56 & 8.97 & 167.5 & $156-186$ \\
\hline BMI & 16 & 19.9 & 2.26 & 19.45 & $16.6-23.9$ \\
\hline ESR after $1 / 2 \mathrm{~h}(\mathrm{~mm} / \mathrm{h})$ & $13 / 5$ & $35.46 / 49.20$ & $25.44 / 37.79$ & $45 / 41$ & $2-80 / 8-90$ \\
\hline CRP (mg/l) & 16 & 25.14 & 46.05 & 8.85 & $2.0-190.6$ \\
\hline Leukocytes (Gpt/l) & 16 & 12.25 & 4.16 & 10.8 & $6.6-21.7$ \\
\hline Total lgG (g/l) & 13 & 17.52 & 5.03 & 18.0 & $10.5-26.4$ \\
\hline Total lgM (g/l) & 12 & 1.58 & 0.36 & 1.59 & $1.09-2.22$ \\
\hline Total $\lg A(g / l)$ & 12 & 3.33 & 1.77 & 2.92 & $1.09-6.58$ \\
\hline Total lgE (kU/l) & 12 & 248.5 & 260.9 & 145.0 & 7.17-672 \\
\hline FEV1 (I)/ (\% predicted) & 15 & $1.77 / 50.45$ & $0.83 / 24.73$ & $1.74 / 42.6$ & $0.77-3.22 / 24.0-109$ \\
\hline IVC (I)/ IVC-P (\% predicted) & 15 & $2.84 / 67.01$ & $0.99 / 20.16$ & $2.44 / 60.0$ & $1.57-4.66 / 41.0-112.0$ \\
\hline MEF25 (I) / MEF25-P (\% predicted) & 15 & $0.47 / 20.89$ & $0.35 / 16.7$ & $0.32 / 13.1$ & $0.11-1.4 / 5.0-70.0$ \\
\hline MEF75/25 (I)/ MEF7525-P (\% predicted) & 15 & $1.03 / 23.97$ & $0.76 / 18.91$ & $0.69 / 16.0$ & $0.24-2.85 / 6.0-74.0$ \\
\hline RV (I)/ RV-P (\% predicted) & 15 & $3.19 / 210.67$ & $1.17 / 71.28$ & $3.02 / 219.0$ & $1.29-4.96 / 99.0-324.0$ \\
\hline Retrieved NL volume prior to therapy (ml) & 16 & 9.15 & 2.08 & 9.25 & \\
\hline Retrieved NL volume during/after therapy $(\mathrm{ml})$ & 16 & 9.94 & 2.19 & 10.50 & \\
\hline
\end{tabular}


Table 2. Clinical and serological characteristics of included patients (nominal variables).

\begin{tabular}{|c|c|c|}
\hline Nominal variables & $\mathbf{n}$ & $\begin{array}{l}\text { Absolute } \\
\text { frequency }\end{array}$ \\
\hline gender (f/m) & 16 & $\begin{array}{c}9(56.3 \%) / \\
7(43.7 \%)\end{array}$ \\
\hline nasal polyps & 16 & $4 / 16(25 \%)$ \\
\hline $\begin{array}{l}\text { history of sinonasal surgery: } \\
\text { once } \\
3 \text { times } \\
\text { adenotomy }\end{array}$ & 16 & $\begin{array}{c}7 / 16(43.8 \%) \\
2 / 16(12.5 \%) \\
1 / 16(6.3 \%)\end{array}$ \\
\hline CRS & 16 & $7 / 16(43.8 \%)$ \\
\hline exocrine pancreatic insufficiency & 16 & $13 / 16(81.3 \%)$ \\
\hline diabetes mellitus & 16 & $9 / 16(56.3 \%)$ \\
\hline hepatopathy & 16 & $3 / 16(18.8 \%)$ \\
\hline $\begin{array}{l}\text { allergic sensitisation to: } \\
\text { Aspergillus fumigatus } \\
\text { house dust mite } \\
\text { grass pollen } \\
\text { pet hair }\end{array}$ & 16 & $\begin{array}{l}11 / 16(68.8 \%) \\
4 / 16(25 \%) \\
2 / 16(12.5 \%) \\
2 / 16(12.5 \%) \\
2 / 16(18.8)\end{array}$ \\
\hline IgG increased & & $8 / 13(61.5 \%)$ \\
\hline IgM increased & 12 & $0 / 12(0 \%)$ \\
\hline $\lg A$ increased & 12 & $3 / 12(25 \%)$ \\
\hline $\lg E$ increased & 12 & $7 / 12(58.3 \%)$ \\
\hline $\begin{array}{l}\text { Therapy: } \\
\text { nasal/topical: } \\
\text { current use of decongestant nose drops } \\
\text { current nasal topical steroids }\end{array}$ & & $\begin{array}{l}1 / 16(6.3 \%) \\
4 / 16(25 \%)\end{array}$ \\
\hline $\begin{array}{l}\text { bronchial: } \\
\text { inhalative anticholinergics } \\
\text { inhalative } \mathrm{NaCl}(0.9 \% \text { or } 6 \%) \\
\text { current inhalative antibiosis } \\
\text { inhalative DNase }\end{array}$ & 16 & $\begin{array}{c}1 / 16(6.3 \%) \\
11 / 16(68.8 \%) \\
11 / 16(68.8 \%) \\
8 / 16(50 \%)\end{array}$ \\
\hline $\begin{array}{l}\text { systemic: } \\
\text { current oral antibiosis } \\
\text { current azithromycin } \\
\text { current antimycotics } \\
\text { current mucolytics } \\
\text { current systemic steroids }\end{array}$ & & $\begin{array}{c}7 / 16(43.8 \% \\
14 / 16(87.5 \%) \\
7 / 16(43.8 \%) \\
13 / 16(81.3 \%) \\
2 / 16(12.5 \%)\end{array}$ \\
\hline
\end{tabular}

By using fluorescence flow cytometry (Sysmex XE-5000, Sysmex Deutschland $\mathrm{GmbH}$, Norderstedt, Germany) total cell count (TCC) and percentages of polymorphonuclear- (PMN) and mononuclear (non-PMN) cells were determined. For differential cell count based on morphology (100 cells) cell pellets were prepared using cytospin (100xg, 3min) and May-Gruenwald staiing technique.

Levels of extracellular DNA were determined in native nasal lavage fluid (NLF) and sputum supernatant at $260 \mathrm{~nm}$ using NanoDrop (NanoDrop ND 1000, PEQLAB, Erlangen, Germany.) For immunological analysis IS supernatant was diluted 1:10 with sterile PBS. As recently described ${ }^{(6)}$ concentrations of IL-4, IL-8, IL-17A, IL-13, RANTES, MPO and sICAM were measured by using a Cytometric Bead Array (FlowCytomix Human Simplex Kits, eBioscience, San Diego, USA) and a flow cytometer (FACSCalibur, BD Biosciences, Franklin Lakes, CA, USA). Results of the analysis were appraised with the FlowCytomix Pro 2.4 software.

\section{Statistics}

Biometrical analysis was performed with MS Excel 2010, IBM SPSS Statistics 20 and GraphPad Prism 5. Dilutions made during procession and analysis of IS were subtracted to obtain values for the native material as obtained from the patient. Concentrations below the detection limit assessed by Cytokine Bead Array were defined as $0.1 \mathrm{ng} / \mathrm{ml}$ below detection limit $(0.1 \mu \mathrm{g} /$ $\mathrm{ml}$, respectively). Longitudinal changes of DNA-content, cell counts and inflammatory mediators were assessed with the Wilcoxon-test for matched pairs while correlations were tested with Spearman's-rho-test for both dates (before and during therapeutic intervention). A value of $p<0.05$ was considered statistically significant. Mann-Whitney-U-Test was performed to compare different groups and odds ratios (OR) were calculated for quantifying how strongly permanent colonization with S. aureus in both airway compartments are associated to each other. Using descriptive statistics clinical characteristics of the study population and test results were pictured.

\section{Results}

\section{Demographic data}

The mean age of the 16 CF-patients ( 9 female/7 male) recruited for this prospective study was 26.25 years (range 21-37, SD 4.6). Eight patients were homozygous for genotype F508del, 7 heterozygous for F508del and one patient homozygous for genotype CFTRdele2,3. In the heterozygous patients class 1-3 mutations (R553X, N1303K) and class 4-5 mutations (R347P, $2789+5 G->A$ ) were found in 2 and 6 patients, respectively. In all but one patient, IV-antibiotic therapy was conducted over 14 days. For clinical reasons this one patient underwent a 28-day treatment. However, the present trial mostly assessed changes within early treatment period by median after 7.5 days (range 3-28 days). Treatment was either started at our CF outpatient clinic, or in hospital and continued as home treatment for most of the patients (11 of 16). Therefore, median hospitalization time resulted in 4 days (range 0 -14).

Therapy was directed against $P$. aeruginosa in 15 patients and additionally against $S$. aureus (6 patients), Haemophilus $(H)$ influenzae (1 patient) and Burkholderia (B) cepacia (1 patient). In one patient it was directed only against $S$. aureus.

Most frequently patients were treated with a double antibio- 
Table 3. Microbiological characteristics of included patients (metric and ordinal variables).

\begin{tabular}{|c|c|c|}
\hline Nominal variables & $\mathbf{n}$ & $\begin{array}{l}\text { Absolute } \\
\text { frequency }\end{array}$ \\
\hline $\begin{array}{l}\text { UAW: detection of pathogenic bacteria and/ } \\
\text { or fungi before } A B\end{array}$ & \multirow{15}{*}{16} & 13/16 (81.3\%) \\
\hline P. aeruginosa & & $9 / 16(56.3 \%)$ \\
\hline non-mucoid & & $3 / 16(18.8 \%)$ \\
\hline mucoid & & $6 / 16(37.5 \%)$ \\
\hline multiresistant & & $2 / 16(12.5 \%)$ \\
\hline intermittent & & $7 / 16(43.8 \%)$ \\
\hline permanent & & $6 / 16(37.5 \%)$ \\
\hline \multirow{3}{*}{$\begin{array}{l}\text { S. aureus } \\
\text { intermittent } \\
\text { permanent }\end{array}$} & & $6 / 16(37.5 \%)$ \\
\hline & & $5 / 16(31.3 \%)$ \\
\hline & & $3 / 16(18.8 \%)$ \\
\hline Enterococcus faecalis & & $2 / 16(12.5 \%)$ \\
\hline Proteus mirabilis & & $1 / 16(6.3 \%)$ \\
\hline E. coli & & $1 / 16(6.3 \%)$ \\
\hline Citrobacter & & $1 / 16(6.3 \%)$ \\
\hline Sphingomonas & & $1 / 16(6.3 \%)$ \\
\hline \multicolumn{3}{|l|}{ LAW: detection of pathogenic bacteria and/ } \\
\hline or fungi before $A B$ & & $15 / 16(93.8 \%)$ \\
\hline P. aeruginosa & & $13 / 16(81.3 \%)$ \\
\hline non-mucoid & & $3 / 16(18.8 \%)$ \\
\hline mucoid & & $10 / 16(62.5 \%)$ \\
\hline multiresistant & & $4 / 16(25 \%)$ \\
\hline intermittent & & $1 / 16(6.3 \%)$ \\
\hline permanent & & $12 / 16(75 \%)$ \\
\hline \multirow{3}{*}{$\begin{array}{l}\text { S. aureus } \\
\text { intermittent } \\
\text { permanent }\end{array}$} & \multirow{3}{*}{16} & $7 / 16(43.8 \%)$ \\
\hline & & $5 / 16(31.3 \%)$ \\
\hline & & $4 / 16(25 \%)$ \\
\hline Enterobacteriae & & $3 / 16(18.8 \%)$ \\
\hline E. coli & & $1 / 16(6.3 \%)$ \\
\hline Yeasts (Candida etc.) & & $4 / 16(25 \%)$ \\
\hline Aspergillus fumigatus & & $3 / 16(18.8 \%)$ \\
\hline Aspergillus flavus & & $1 / 16(6.3 \%)$ \\
\hline Sphingomonas & & $1 / 16(6.3 \%)$ \\
\hline Corynebacteriae & & $1 / 16(6.3 \%)$ \\
\hline Haemophilus parainfluenza & & $1 / 16(6.3 \%)$ \\
\hline Burkholderia cepacia & & $1 / 16(6.3 \%)$ \\
\hline
\end{tabular}

According the criteria published by Lee et al. (34) "permanent colonization" was defined as at least $50 \%$ of cultures within the last year were found positive and "intermittent" as less than $50 \%$ of cultures within the last year were found positive.

tic combination that contained meropenem and tobramycin (14/16). Adjusted to clinical conditions, infection status and resistance situation, IV-therapy was modified or supplemented with antibiotic agents as ceftazidim (1/16), ciprofloxacin (1/16), piperacillin-tazobactam (1/16) and vancomycin (1/16). $25 \%$ (4 patients) of our study population were affected by nasal polyps while 11 patients (68.8\%) already had a history of sinonasal surgery ( 9 patients had a polypectomy, one patient an adenoidectomy and one patient surgery of the nasal septum done). Furthermore, CRS criteria according to the EPOS 2008

\section{NL recovery volumes}

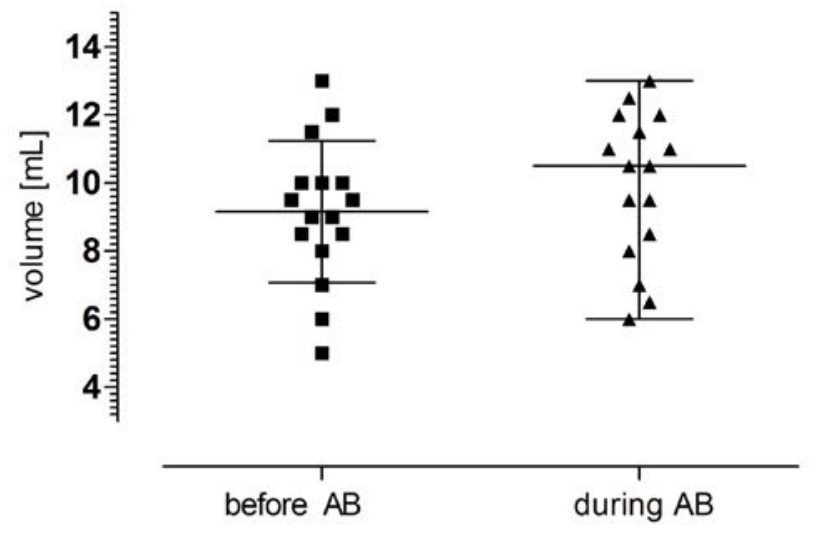

Figure 1. NL backflow volume after IV-antibiotic treatment was slightly higher than the retrieved volume of NL before therapeutic intervention (median $10.5 \mathrm{~mL}$, range 6.00-13.00, and median $9.25 \mathrm{ml}$, range 5.0013.00 , respectively).

criteria ${ }^{(33)}$ were fulfilled by 7 patients (43.8\%).

As concomitant CF manifestation of other organ systems exocrine pancreatic insufficiency was present in 13 patients (81.3\%), diabetes mellitus and hepatopathy in $9(56.3 \%)$ and $3(18.8 \%)$ patients, respectively. Allergic sensitization was frequent in our study population, mostly to Aspergillus fumigatus (11 patients, $68.8 \%)$. Moreover, house dust mite $(1 / 16,6.3 \%)$, grass pollen $(2 / 16,12.5 \%)$, pet hair $(2 / 16,12.5 \%)$ and cows' milk protein $(1 / 16$, $6.3 \%)$ were represented as allergens. Detailed clinical and serological data are presented in Tables 1 and 2.

\section{Serological data}

Systemic inflammation parameters like erythrocyte sedimentation rate (ESR) were elevated before the start of IV antibiotic treatment in $76.9 \%$ (10/13, median $1 \mathrm{~h} 45$, range $1 \mathrm{~h} 2-80)$, CRP in $62.5 \%$ (10/16, median 8.85, range 2.0-190.6), and leucocytes in $43.8 \%$ (7/16, median 10.8 , range $6.6-21.7)$ of patients. IgG was found elevated in $61.5 \%$ of patients (8/13, median 18.00 $\mathrm{g} / \mathrm{l}$, range $10.5-26.40 \mathrm{~g} / \mathrm{l})$, IgA in $25 \%$ (3/12, median $2.91 \mathrm{~g} / \mathrm{l}$, range 1.54-6.58 g/l), and IgE in 58.3\% (7/12, median $145.00 \mathrm{kU} / \mathrm{l}$, range $7.17-672.0 \mathrm{kU} / \mathrm{l})$. IgM was within the normal range in all 16 patients (median $1.59 \mathrm{~g} / \mathrm{l}$, range 1.09-2.22 $\mathrm{g} / \mathrm{l}$ ).

\section{Methodological issues}

NL backflow volume after IV-antibiotic treatment was slightly higher than NL recovery before therapeutic intervention (median $10.5 \mathrm{~mL}$, range 6.00-13.00, respective median $9.25 \mathrm{ml}$, range 5.00-13.00, (Figure 1), but differences did not reach statistical significance $(p=0.49)$. 


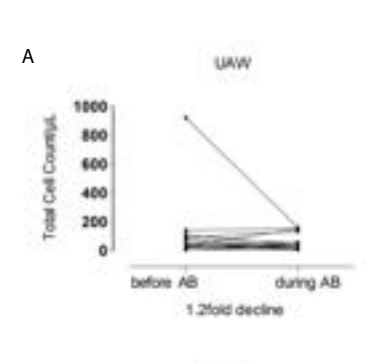

TCC

B

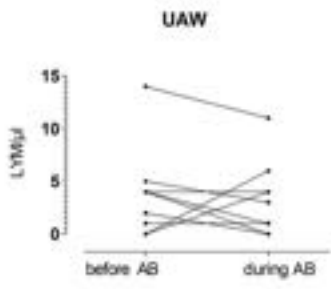

Lymphocytes
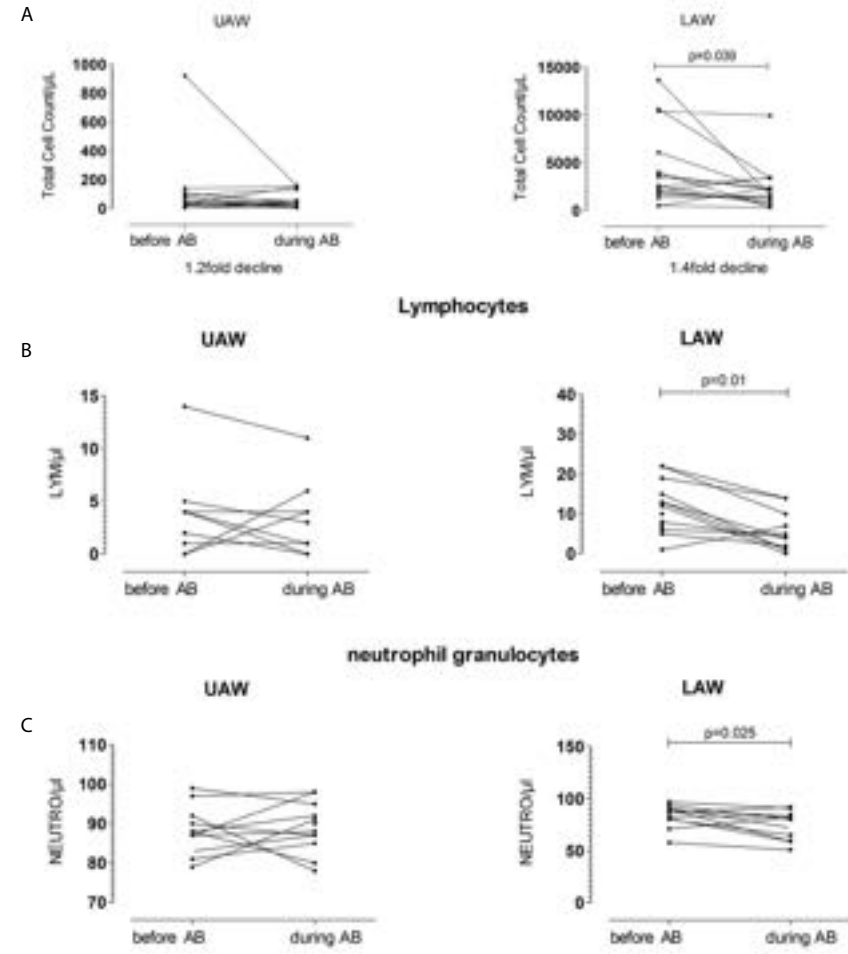

neutrophil granulocytes

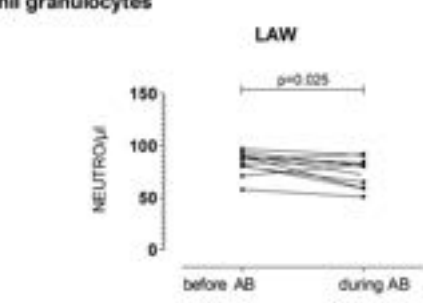

D

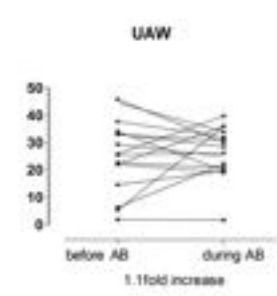

DNA

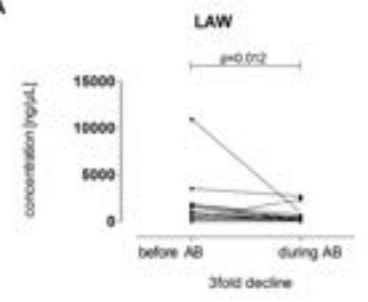

Figure 2. Differences in changes of total cell count and DNA concentration in UAW and LAW. In UAW declines of TCC did not reach statistical significance. Median values declined 1.2-fold during IV therapeutic intervention (A). TCC in LAW declines significantly $(p=0.039)$ during IVantibiosis. Median values declined 1.4-fold (B). No significant changes of DNA concentration in UAW during IV-antibiosis. Median values increased slightly (1.1-fold, C). Significant decline of DNA concentrations in LAW during IV-antibiosis ( $p=0.012)$, median values decline 3 -fold (D).

Cytological analysis in NL and sputum

Total cell counts (TCC) and distinction of polymorphonuclear neutrophils PMN and monomorphonuclear leucocytes (MN, resp. non-PMN) was performed for all 16 patients on both dates, and differential cell count for 11 patients. Changes for UAW cytology and significant declines for LAW are shown in Table 4 and Figure 2. Further on, changes correlated with changes of IL-8 LAW $(r=0.547, p=0.028)$ and with the decline $(r=0.507, p$ $=0.045)$.

DNA

During the therapeutic intervention, DNA concentration decre- ased significantly in LAW ( $\mathrm{n}=16$, before IV-AB: median: 817.99 $\mathrm{ng} / \mu \mathrm{l}$; during IV-AB: median: $275.14 \mathrm{ng} / \mu \mathrm{l} ; \mathrm{p}=0.012$ ), whereas only a slight, but not significant, increase was found in UAW samples ( $n=16$, before IV-AB: median: $25.75 \mathrm{ng} / \mu \mathrm{l}$; during IV-AB: median: $26.45 \mathrm{ng} / \mu \mathrm{l} ; \mathrm{p}=0.86$ ).

\section{Microbiological analysis}

Before $A B$ treatment pathogenic bacteria and fungi were detected in 13/16 (81.3\%) and 15/16 (93.8\%) patients for UAW resp. LAW. Distributions and details are shown in Table 3. The most frequently detected pathogen was P. aeruginosa (UAW: $56.3 \%$ LAW: $81.3 \%$ ) followed by S. aureus (UAW: 37.5\%, LAW: 43.8\%). Permanent colonization of $P$. aeruginosa for UAW resp. LAW was found in $37.5 \%$ and $75 \%$ and of S. aureus in $18.8 \%$ and $25 \%$ of patients, respectively. In our cohort, the risk of permanent $P$. aeruginosa colonization in LAW was increased by a factor of $6.6(\mathrm{Cl}$ =95\%: 0.2908-149.7819, $\mathrm{p}=0.236$ ) if UAW were also chronically infected. Odds for consistent S. aureus infection in LAW in case of permanently infected UAW are increased by factor $58.3(\mathrm{Cl}=$ 95\%: 1.9215-1770.9393, $p=0.019$ ). Further on, in LAW overall concentrations of MPO ( $p=0.025$, mean rank 9.77) and IL-8 ( $p$ $=0.039$, mean rank 9.65 ) revealed to be significantly higher in $P$. aeruginosa positive samples than in non-colonized patients (MPO: mean rank 3.0; IL-8: mean rank 3.5) whereas median values of IL-8 ( $P$. aeruginosa positive $16287.03 \mathrm{pg} / \mathrm{ml}$, $P$. aeruginosa negative $7419.14 \mathrm{pg} / \mathrm{ml}$ ) and MPO ( $P$. aeruginosa positive $4359.95 \mathrm{ng} / \mathrm{ml}$, P. aeruginosa negative $3079.42 \mathrm{ng} / \mathrm{ml}$ ) showed only a trend toward significance (MPO: $p=0.055, \mathrm{IL}-8: \mathrm{p}=0.055$ ).

Changes of inflammatory markers during intravenous antibiotic therapy

Concentrations of MPO and IL-8 significantly decreased in both, the UAW and LAW after antibiotic therapy of 7.5 days (MPO-

UAW: $p=0.011$, IL-8-UAW: $p=0.008$, respectively MPO-LAW: $p=$ 0.003 , IL-8-LAW: $p=0.003$ ). Interestingly, the decline was much less pronounced in the UAW compared to the LAW: median values for IL-8 declined 1.9-fold in UAW, respectively, 3-fold in LAW (Figure 3). MPO in NL declined 1.8-fold, respectively, 9.8-fold in LAW (Figure 3). The same tendency applies to IL-13 $(p=0.285)$ in UAW, while IL-4 showed a trend to increase $(p=0.625)$. In LAW detection frequencies were below the detection limit for IL-17A and sICAM while RANTES could be detected only in very low frequencies being insufficient for any statistical assessment. During antibiotic intervention, decreases of IL-8-UAW and neutrophil granulocytes UAW correlated significantly $(r=0.653$, $\mathrm{p}=0.029, \mathrm{n}=11$ ) as well as the dynamics of IL-13-UAW and IL-4-UAW $(r=0.816, p<0.001)$. An inverse correlation was found between the declines of TCC-UAW and IL-13-UAW ( $r=-0.592$, $p=0.016)$. In addition, we detected a significant correlation between the decreases of MPO-LAW and IL-8-LAW ( $r=0.579, p=$ 0.019). Moreover, we observed a correlation between declines of 


\section{MPO}
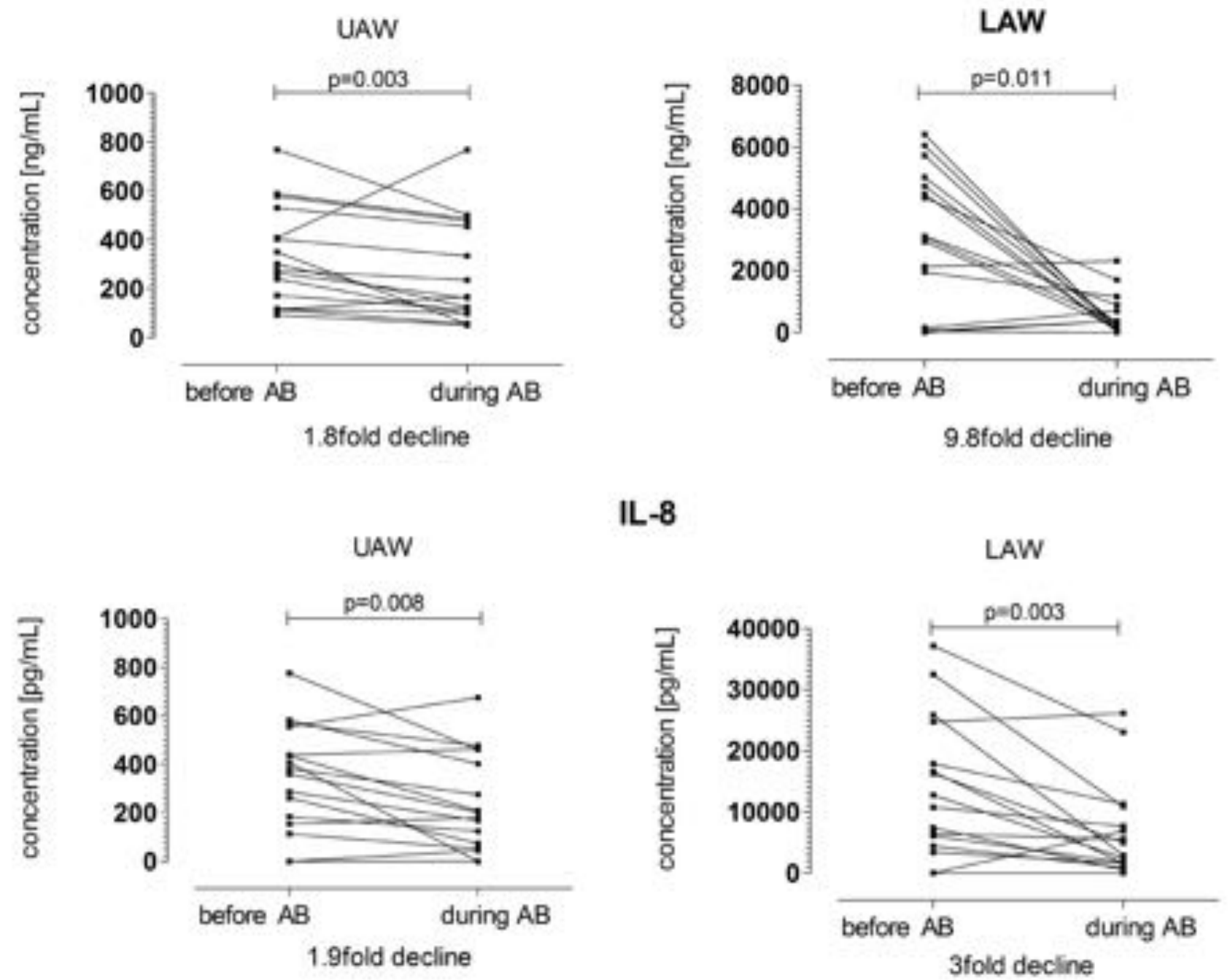

\section{IL-8}

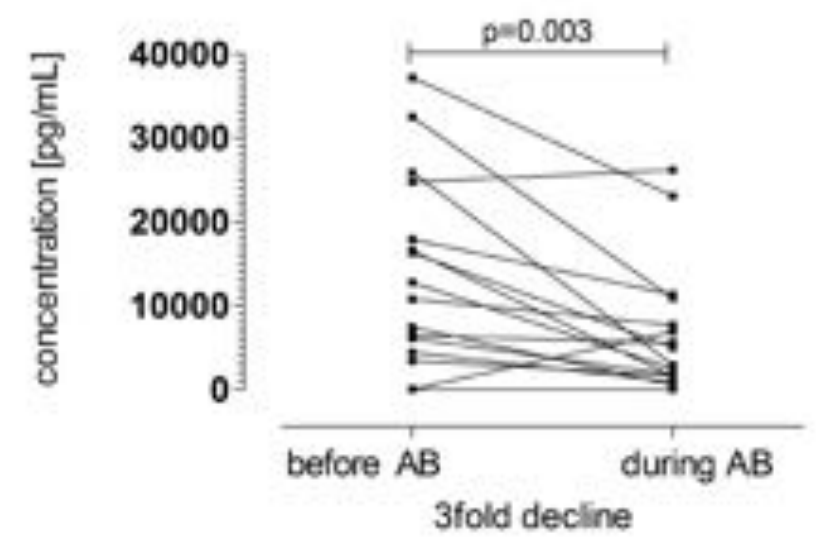

Figure 3. Differences of IL-8 and MPO in upper and lower airways before and during IV-antibiotic treatment. A) MPO declines significantly in the UAW $(p=0.003)$ and in the LAW $(p=0.011)$. However, median decline only results 1.8 -fold in the UAW but 9.8-fold in the LAW. B) IL-8 also decreases significantly in UAW ( $p=0.008)$ and in the LAW $(p=0.003)$. Thereby, median values decline 1.9-fold in the UAW and 3-fold in the LAW.

MPO-LAW and MPO-LAW and activated monocytes LAW, respectively, IL-8-LAW and activated lymphocytes LAW $(r=0.679, p=$ $0.022, n=11$, respectively, $r=0.632, p=0.037, n=11$ ).

Correlation of inflammatory markers before and during $A B$ Before and during AB treatment IL-8-UAW correlated significantly with MPO-UAW ( $n=16, r=0.64, p=0.008$, respectively, $r$ $=0.646, p=0.007)$. IL-8-UAW correlations with TCC-UAW $(n=16$, $r=0.52, p=0.039)$ and eosinophil granulocytes UAW $(n=12, r=$ $0.777, p=0.003$ ) could be shown only prior to therapy. Further on, correlations between IL-4-UAW and IL-13-UAW were found before, respectively, during $A B$ therapy $(n=16, r=0.806, p=$ 0.00016 , respectively, $r=0.715, p=0.002$ ). Changes of IL-8-LAW did correlate with changes of MPO-LAW $(r=0.741, p=0.001)$ and DNA-LAW $(r=0.693, p=0.003)$.

\section{Discussion}

The relevance of pathogen related rhinosinusitis in general health and its financial consequences have been massively underestimated. Additionally, resulting antibiotic treatments are related to complications and relevantly contribute to development of antibiotic resistances. Thereby antibiotic treatment of bacterial rhinosinusitis empirically was shown to require prolonged periods of therapy, but this issue has not been understood sufficiently.

Our results from a cohort of cystic fibrosis patients receiving 
Table 4. Cytological changes and DNA-Concentration in UAW and LAW prior and after IV AB therapy.

\begin{tabular}{|c|c|c|c|c|c|c|}
\hline \multirow[b]{2}{*}{ Sputum (LAW) } & \multirow[b]{2}{*}{$\mathbf{n}$} & \multicolumn{2}{|c|}{ before IV-antibiotic therapy } & \multicolumn{2}{|c|}{ during IV-antibiotic therapy } & \multirow[b]{2}{*}{ p-value } \\
\hline & & median & range & median & range & \\
\hline TCC [cells/ml] & 16 & 2571.5 & $488-13651$ & 1875 & $307-9923$ & 0.039 \\
\hline LYM [\%] & 11 & 12.5 & $1-36$ & 4 & $0-14$ & 0.01 \\
\hline NEUTRO [\%] & 11 & 87 & $58-97$ & 81 & $51-92$ & 0.025 \\
\hline DNA [ng/ul] & 16 & 818.0 & & 275.1 & & 0.012 \\
\hline NL (UAW) & $\mathbf{n}$ & median & range & median & range & p-value \\
\hline TCC [cells/ml] & 16 & 40.5 & 5-922 & 33.5 & $7-161$ & 0.336 \\
\hline LYM [\%] & 11 & 4 & $0-14$ & 3 & $0-11$ & 0.539 \\
\hline NEUTRO [\%] & 11 & 88 & 79-99 & 89 & $78-98$ & 0.650 \\
\hline DNA [ng/ul] & 16 & 25.8 & & 27.5 & & 0.860 \\
\hline
\end{tabular}

systemic intravenous antibiotic treatment can add knowledge to this topic. To some extent, CF could serve as a model for pathogen-related CRS as the patients almost regularly reveal upper and lower airway colonization with pathogenic bacteria and rhinosinusitis is frequent in the inherited disease ${ }^{(6-10)}$. However, it has to be taken in mind, that CF regularly is associated to impaired mucociliary clearance, unlike CRS in primary healthy individuals.

We assessed changes in cytokine expression, extracellular DNA concentration and cytological dynamics in NL and sputum of 16 CF patients after a median period of 7.5 days of intravenous antibiotic treatment directed against pulmonary colonization with pathogens like P. aeruginosa, S. aureus and/or H. influenzae. Most interestingly, inflammatory markers in the upper airways showed a reduced decline under this treatment, in contrast to markers in lower airway secretions. IV-antibiotic treatment significantly reduced total cell counts (TCC) in induced sputum and the proportion of neutrophils, known as the major player in LAW inflammation ( $\mathrm{p} \mathrm{TCC}=0.039$. p neutrophils $=0.025$ ). In contrast, this therapy did not affect such a reduction in upper airway secretions ( $p$ TCC $=0.336$, $p$ neutrophils $=0.650$ ). Whereas for the LAW our findings are in good accordance to published studies $(28,35,36)$, previously only a few investigations were performed to assess effects of IV-antibiotics on inflammation in the UAW ${ }^{22,}$ 37). This to our knowledge is the first study to compare changes of inflammatory markers in UAW and LAW during IV-antibiotic treatment in CF.

MPO and IL-8 play an important role in CF patients' immune response to pathogen colonization in both airway compartments.
According to previous studies levels for both cytokines are increased in CF upper and lower airways, correlating significantly among each other. While IL-8 is the major neutrophil chemoattractant derived from innate immune cells and Th1 lymphocytes after stimulation through different pathways, the neutrophilreleased MPO is a well-established marker for neutrophil activity $(6,38,39)$. Despite reaching statistical significance in both airway levels, declines of IL-8 and MPO after a median of 7.5 days of IV-antibiotic treatment were much lower in the sinonasal compartment than in the LAW (MPO LAW 9.8-fold respective UAW 1.8-fold, IL-8 LAW 3-fold, respectively, UAW 1.9-fold).

In accordance with previous studies of Hentschel et al. (29), respectively, Fischer et al. ${ }^{(30)}$ a correlation of IL-8 and MPO levels was seen prior to and during IV-therapy in UAW. Further on,

TCC in LAW correlated with IL-8 and extracellular DNA during antibiotic IV-treatment. Both, IL-8 and extracellular DNA correlated also among each other.

Extracellular DNA measured in NL and sputum originates predominantly from necrotic neutrophils and conforms neutrophil extracellular traps (NETs) ${ }^{(40)}$. This composition of decondensed chromatin and neutrophil antimicrobial proteins degrades virulence factors and plays a role in killing of bacteria ${ }^{(41)}$. Interestingly, we observed a significant decline of DNA in sputum $(p=0.012)$ during antibiotic treatment, while in NL even a slight increase of DNA was measured, again supporting the hypothesis of reduced therapeutic success in the sinonasal compartment. Altogether, the present study reveals different changes of IL-8, MPO, DNA, neutrophils, and the TCC affected by IV-antibiotic therapy among the upper and lower airway levels. In the ongoing process aiming to understand similarities and differences 
of both airway levels' immune responses toward colonization and infection with pathogens ${ }^{(8,22)}$ these results can give further hints.

Inflammatory responses in the sinonasal area appear to be reached with delayed or even with reduced effects by a systemic, intravenous antibiotic treatment compared to a systemic pulmonary therapy. Possible reasons are differences in the immune response between UAW and LAW in CF patients as reported previously ${ }^{(8,22)}$. Additionally, the anatomical character of paranasal sinuses leads to insufficient reachability by systemic antibiotics: the hollow organs are not as vascularised as the parenchymal lungs, and, similar to abscesses, they are often filled with purulent secretions or mucoceles as a result of remittent or chronic pathogen colonization.

Assessment of UAW colonization has not been part of routine CF care during the last decades, according to most international consensus statements. Only recently, the UAW role in pathogen acquisition and persistence is coming into the clinical and scientific focus $(8,9,17,18,20,22,30,42)$. Thereby, findings in CF-related rhinosinusitis, which regularly is associated with pathogen colonization, are not only relevant for the care of patients with the inherited disease. Moreover, these trials give essential new insights for the large number of patients with acute and chronic bacterial rhinosinusitis of other origins. In this regard, the detected insufficiency of systemically applied antibiotics in CF patients colonized with pathogens on sinonasal inflammatory markers reveal the following: approaches to apply antibiotics at the site of bacterial infection within the sinuses require further assessment. For the lungs, topical inhalation of antipseudomonal antibiotics is a golden standard, besides IV-antibiotic therapy. Bronchial inhalation provides the highest concentrations of antibiotics within sputum together with low side effects as no relevant blood levels are reached.

As the paranasal sinuses are not reached by conventional inhalation ${ }^{(43)}$, our studies' results may indicate, that sinonasal surgery with widening of sinonasal ostia can be required in some chronic bacterial rhinosinusitis to allow nasal lavages with addition of antibiotics reach the paranasal sinuses. This approach recently has been taken in a large Danish cohort, postoperatively flushing the sinonasal space with colomycin ${ }^{(22)}$.

On the other hand case reports ${ }^{(18)}$ and a very recent pilot study on topical antibiotic administration via pulsating sinonasal inhalation could be a promising alternative for reducing respectively eradicating pathogen colonization in UAW ${ }^{(44,45)}$. In CF both approaches could help to prevent chronic sinonasal infection with $P$. aeruginosa and a consecutive expansion to the lungs.

Regarding anatomical conditions our publication is relevant to any other bacterial related infection of the paranasal sinuses. Findings in the present study are in good accordance with empirical observations showing the need to treat bacterial sinusitis for much longer periods with systemic antibiotics than required for other infections of parenchymal organs. Consistently, there is a lack of evidence reported for the short-term use ( $<4$ weeks) of systemic antibiotics, whereas patients with CRSsNP may benefit from a long-term therapy with macrolides in low doses ${ }^{3,}$ 5,46 . The beneficial effect of this low-dose-therapy, that takes at least 12 weeks, harks back to macrolides' immune-modulatory properties, but again is linked to the risk of increasing antibiotic resistances ${ }^{(3,46)}$.

\section{Possible limitations}

A direct comparison of mediator concentrations in NL and sputum is difficult. Thereby, we added no dilution factor to NL but for sputum samples a dilution factor 10 was used for sample processing. However, by comparing changes in upper- and lower airway concentrations of inflammatory mediators during therapy a correction e.g. to the backflow volume and the protein content did not influence our results ${ }^{(6)}$.

For future work it would be very helpful to administer a best practice guideline for sputum preparation to achieve greater comparability of different studies. Further on, for NLF as well as for BALF and sputum no suitable 'housekeeping' markers have been identified for normalization to improve standardization, which hampers the inter-study comparability ${ }^{(47)}$.

Following trials should include assessment of changes in microbiological findings and antibiotic resistances after IV-antibiotic treatment in CF. Also monitoring of rhinoscopic changes before and after finalisation of a 14 days standard IV-antibiotic treatment in CF would be interesting. These issues have not been included in the present trial which focuses on changes in inflammatory mediators during early phases of IV-AB therapy.

\section{Conclusion}

The present study identifies for the first time a substantially reduced effect of IV-antibiotic treatments on sinonasal- compared to pulmonary inflammatory markers. Accordingly, our results reveal a limited potential of systemic antibiotic treatment to control sinonasal bacterial infections. We contribute this to the anatomical situation of paranasal sinuses, which are not reached effectively by systemic antibiotics. We suppose that our findings do not only apply to CF related chronic rhinosinusitis, but it can be taken for bacterial CRS of other origin as well.

\section{Abbreviations/Glossary}

AB (antibiotic), CF (Cystic Fibrosis), CFTR (Cystic Fibrosis Transmembrane Conductance Regulator), CRS (Chronic Rhino- 
sinusitis), NP (nasal polyps), NLF (Nasal lavage fluid), NL (Nasal lavage), BALF (bronchoalveolar lavage fluid), IS (induced sputum), UAW (upper airways), LAW (lower airways), TCC (total cell count), PMN (polymorphonuclear), MN (mononuclear), NE (neutrophil elastase), IL (interleukin), MPO (myeloperoxidase), RANTES (regulated on activation, normal T cell expressed and secreted), IV (intravenous), soluble intercellular adhesion molecule-1 (sICAM), AB (antibiotic), LTx (Lung transplantation)

\section{Acknowledgements}

We thank Andrea Kremlitschka, Christiane Fischer and Jürgen Sonnemann for their assistance. We thank Lars Döbert for critical proof reading of the manuscript. The authors especially thank the patients who participated in the study.

\section{Author contributions}

FD, JH and JGM elaborated the study concept and were the principal investigators, writing the manuscript. FD conducted the study with support of NF. TL contributed to the analysis and interpretation of data together with FD, JH and NF. URM, KB, and WP were our partners in the participating laboratories. WP and MWP supported the study regarding microbiological and infectiological issues and OGL regarding specific ENT issues.

\section{Conflict of interest}

We confirm that there are no known conflicts of interest associated with this publication. Neither there have been personal relationships with other people or organizations nor significant financial support for this work that could have influenced its outcome.

\section{References}

1. Hastan D, Fokkens WJ, Bachert C, et al Chronic rhinosinusitis in Europe--an underestimated disease. A GA(2)LEN study Allergy. 2011; 66: 1216-1223.

2. Tan BK, Kern RC, Schleimer RP, Schwartz BS. Chronic rhinosinusitis: the unrecognized epidemic. Am J Respir Crit Care Med. 2013; 188: 1275-1277.

3. Fokkens WJ, Lund VJ, Mullol J, et al. EPOS 2012: European position paper on rhinosinusitis and nasal polyps 2012. A summary for otorhinolaryngologists. Rhinology. 2012; 50: 1-12.

4. Bachert C, Van Bruaene N, Toskala E, et al Important research questions in allergy and related diseases: 3-chronic rhinosinusitis and nasal polyposis - a GA2LEN study. Allergy. 2009; 64: 520-533.

5. Hamilos DL. Chronic rhinosinusitis: epidemiology and medical management. J Allergy Clin Immunol. 2011; 128: 693-707.

6. Beiersdorf N, Schien M, Hentschel J, Pfister W, Markert UR, Mainz JG. Soluble inflammation markers in nasal lavage from CF patients and healthy controls. J Cyst Fibros. 2013; 12: 249-257.

7. Rowe SM, Miller S, Sorscher EJ. Cystic fibrosis. N Engl J Med. 2005; 352: 1992-2001.

8. Johansen HK, Aanaes K, Pressler T, et al. Colonisation and infection of the paranasal sinuses in cystic fibrosis patients is accompanied by a reduced PMN response. J Cyst Fibros. 2012; 11: 525-531.

9. Mainz JG, Naehrlich L, Schien M, et al. Concordant genotype of upper and lower airways $P$ aeruginosa and $S$ aureus isolates in cystic fibrosis. Thorax. 2009; 64: 535-540.

10. Robertson JM, Friedman EM, Rubin BK. Nasal and sinus disease in cystic fibrosis. Paediatr Respir Rev. 2008; 9: 213-219.

11. Oomen KP, April MM. Sinonasal manifestations in cystic fibrosis. Int J Otolaryngol. 2012; 2012: 789572

12. Mainz JG, Koitschev A. Pathogenesis and
Management of Nasal Polyposis in Cystic Fibrosis. Curr Allergy Asthma Rep. 2012; 12: 163-174.

13. Eggesbo HB, Sovik S, Dolvik S, Kolmannskog F. CT characterization of inflammatory paranasal sinus disease in cystic fibrosis. Acta Radiol. 2002; 43: 21-28.

14. Wieser R. [Cystic fibrosis--the most frequent life-shortening autosomal recessive disease]. Wien Med Wochenschr. 2005; 155: 268-272.

15. Boucher RC. Evidence for airway surface dehydration as the initiating event in CF airway disease. J Intern Med. 2007; 261: 5-16.

16. Sagel SD, Accurso FJ. Monitoring inflammation in CF. Cytokines. Clin Rev Allergy Immunol. 2002; 23: 41-57

17. Mainz JG, Michl R, Pfister W, Beck JF. Cystic fibrosis upper airways primary colonization with Pseudomonas aeruginosa: eradicated by sinonasal antibiotic inhalation. Am J Respir Crit Care Med. 2011; 184: 1089-1090.

18. Mainz JG, Hentschel J, Schien C, et al. Sinonasal persistence of Pseudomonas aeruginosa after lung transplantation. J Cyst Fibros. 2012; 11: 158-161.

19. Walter S, Gudowius P, Bosshammer J, et al. Epidemiology of chronic Pseudomonas aeruginosa infections in the airways of lung transplant recipients with cystic fibrosis. Thorax. 1997; 52: 318-321.

20. Hansen SK, Rau MH, Johansen HK, et al. Evolution and diversification of Pseudomonas aeruginosa in the paranasal sinuses of cystic fibrosis children have implications for chronic lung infection. ISME J. 2012; 6: 31-45.

21. Kolpen M, Hansen CR, Bjarnsholt $T$, et al. Polymorphonuclear leucocytes consume oxygen in sputum from chronic Pseudomonas aeruginosa pneumonia in cystic fibrosis. Thorax. 2010; 65: 57-62.

22. Aanaes K. Bacterial sinusitis can be a focus for initial lung colonisation and chronic lung infection in patients with cystic fibro- sis. J Cyst Fibros. 2013; 12 Suppl 2: S1-S20.

23. Frederiksen B, Koch C, Hoiby N. Antibiotic treatment of initial colonization with Pseudomonas aeruginosa postpones chronic infection and prevents deterioration of pulmonary function in cystic fibrosis. Pediatr Pulmonol. 1997; 23: 330-335.

24. Breen L, Aswani N. Elective versus symptomatic intravenous antibiotic therapy for cystic fibrosis. Cochrane Database Syst Rev. 2012; 7: CD002767.

25. Doring G, Flume P, Heijerman H, Elborn JS. Treatment of lung infection in patients with cystic fibrosis: current and future strategies. J Cyst Fibros. 2012; 11: 461-479.

26. Mussaffi $H$, Fireman EM, Mei-Zahav M, Prais $D$, Blau $H$. Induced sputum in the very young: a new key to infection and inflammation. Chest. 2008; 133: 176-182.

27. Nicholas B, Djukanovic R. Induced sputum: a window to lung pathology. Biochem Soc Trans. 2009; 37: 868-872.

28. Ordonez CL, Henig NR, Mayer-Hamblett N, et al. Inflammatory and microbiologic markers in induced sputum after intravenous antibiotics in cystic fibrosis. Am J Respir Crit Care Med. 2003; 168: 1471-1475.

29. Hentschel J, Muller U, Doht F, et al. Influences of nasal lavage collection-, processing- and storage methods on inflammatory markers - Evaluation of a method for non-invasive sampling of epithelial lining fluid in cystic fibrosis and other respiratory diseases. J Immunol Methods. 2014; 404: 41-51.

30. Fischer N, Hentschel J, Markert UR, Keller PM, Pletz MW, Mainz JG. Non-invasive assessment of upper and lower airway infection and inflammation in CF patients. Pediatr Pulmonol. 2014; 49: 1065-1075.

31. Pitrez PM, Brennan S, Turner S, Sly PD. Nasal wash as an alternative to bronchoalveolar lavage in detecting early pulmonary inflammation in children with cystic fibrosis. Respirology. 2005; 10: 177-182. 
32. Mauch H, Qualitätsstandards EM-I. MiQ: Qualitätsstandards in der mikrobiologischinfektiologischen Diagnostik: Elsevier, Urban \& Fischer; 1999.

33. Lee TW, Brownlee KG, Conway SP, Denton M, Littlewood JM. Evaluation of a new definition for chronic Pseudomonas aeruginosa infection in cystic fibrosis patients. J Cyst Fibros. 2003; 2: 29-34.

34. Thomas M, Yawn BP, Price D, Lund V Mullol J, Fokkens W. EPOS Primary Care Guidelines: European Position Paper on the Primary Care Diagnosis and Management of Rhinosinusitis and Nasal Polyps 2007 a summary. Prim Care Respir J. 2008; 17: 79-89.

35. Chiron R, Grumbach YY, Quynh NV, Verriere V, Urbach V. Lipoxin A(4) and interleukin-8 levels in cystic fibrosis sputum after antibiotherapy. J Cyst Fibros. 2008; 7: 463-468.

36. Noah TL, Ivins SS, Abode KA, et al. Inhaled versus systemic antibiotics and airway inflammation in children with cystic fibrosis and Pseudomonas. Pediatr Pulmonol. 2010; 45: 281-290.

37. Paats MS, Bergen IM, Bakker M, et al. Cytokines in nasal lavages and plasma and their correlation with clinical parameters in cystic fibrosis. J Cyst Fibros. 2013; 12: 623629.

38. Kettle AJ, Chan T, Osberg I, et al. Myeloperoxidase and protein oxidation in the airways of young children with cystic fibrosis. Am J Respir Crit Care Med. 2004; 170): 1317-1323.
39. Van der Vliet A, Nguyen MN, Shigenaga MK, Eiserich JP, Marelich GP, Cross CE. Myeloperoxidase and protein oxidation in cystic fibrosis. Am J Physiol Lung Cell Mol Physiol. 2000; 279: L537-546.

40. Papayannopoulos V, Staab D, Zychlinsky A Neutrophil elastase enhances sputum solubilization in cystic fibrosis patients receiving DNase therapy. PLoS One. 2011; 6: e28526.

41. Brinkmann V, Reichard U, Goosmann C, et al. Neutrophil extracellular traps kill bacteria. Science. 2004; 303: 1532-1535.

42. Aanaes K, Johansen HK, Skov M, et al. Clinical effects of sinus surgery and adjuvant therapy in cystic fibrosis patients - can chronic lung infections be postponed? Rhinology. 2013; 51: 222-230.

43. St Martin MB, Hitzman CJ, Wiedmann TS, Rimell FL. Deposition of aerosolized particles in the maxillary sinuses before and after endoscopic sinus surgery. Am J Rhinol. 2007; 21: 196-197.

44. Mainz JG, Schädlich K, Schien C, et al. Sinonasal inhalation of tobramycin vibrating aerosol in cystic fibrosis patients with upper airway Pseudomonas aeruginosa colonization: results of a randomized, doubleblind, placebo-controlled pilot study. Drug Des Devel Ther. 2014; 8: 209-217.

45. Stanojevic S, Waters V, Mathew JL, Taylor L, Ratjen F. Effectiveness of inhaled tobramycin in eradicating Pseudomonas aeruginosa in children with cystic fibrosis. J Cyst Fibros. 2014; 13: 172-178.

46. Piromchai $P$, Thanaviratananich $S$,
Laopaiboon M. Systemic antibiotics for chronic rhinosinusitis without nasal polyps in adults. Cochrane Database Syst Rev. 2011; CD008233.

47. Muhlebach M, Miller M, Moore C, Wedd J, Drake A, Leigh M. Are lower airway or throat cultures predictive of sinus bacteriology in cystic fibrosis? Pediatr Pulmonol. 2006; 41: 445-451.

Jochen G. Mainz

Cystic Fibrosis Centre

Department of Paediatrics

Jena University Hospital

Kochstr. 2

07743 Jena

Germany

Tel: +49-3641-938425

Fax: +49-3641-938 314

E-mail:

Jochen.Mainz@med.uni-jena.de

Table S1. Medians and ranges of relevant measured inflammatory mediators.

\begin{tabular}{|c|c|c|c|c|c|c|c|c|}
\hline \multicolumn{3}{|c|}{ upper airways } & \multicolumn{3}{|c|}{ before IV-AB } & \multicolumn{3}{|c|}{ during IV-AB } \\
\hline mediator & unit & DL & median & range & frequency & median & range & frequency \\
\hline MPO & $\mathrm{ng} / \mathrm{mL}$ & 0.02 & 288.85 & $92.98-769$ & $16 / 16$ & 165.02 & $51.5-768.05$ & $16 / 16$ \\
\hline IL-8 & $\mathrm{pg} / \mathrm{mL}$ & 0.5 & 372.08 & $0.4-775.54$ & $14 / 16$ & 192.31 & $0.4-676.83$ & $14 / 16$ \\
\hline IL-4 & $\mathrm{pg} / \mathrm{mL}$ & 20.8 & 20.7 & $12.88-752.45$ & $8 / 16$ & 20.7 & $16.78-369.37$ & $6 / 16$ \\
\hline II-13 & $\mathrm{pg} / \mathrm{mL}$ & 4.5 & 230.78 & $4.4-893.33$ & $10 / 16$ & 175.39 & $4.4-659.97$ & $11 / 16$ \\
\hline \multicolumn{3}{|c|}{ lower airways } & \multicolumn{3}{|c|}{ before IV-AB } & \multicolumn{3}{|c|}{ during IV-AB } \\
\hline mediator & unit & DL & median & range & frequency & median & range & frequency \\
\hline MPO & $\mathrm{ng} / \mathrm{mL}$ & 0.02 & 3095.4 & $0.02-6412.13$ & $16 / 16$ & 316.58 & $0.02-2315.44$ & $16 / 16$ \\
\hline IL-8 & $\mathrm{pg} / \mathrm{mL}$ & 0.5 & 11754.91 & $0.4-37169.74$ & $16 / 16$ & 3936.805 & $0.4-25160.17$ & $16 / 16$ \\
\hline IL-4 & $\mathrm{pg} / \mathrm{mL}$ & 20.8 & 20.7 & $20.7-20.7$ & $16 / 16$ & 20.7 & $20.7-148.83$ & $16 / 16$ \\
\hline ||-13 & $\mathrm{pg} / \mathrm{mL}$ & 4.5 & 4.40 & $4.4-2538.55$ & $16 / 16$ & 4.4 & $4.4-2705.36$ & $16 / 16$ \\
\hline
\end{tabular}

